\title{
Review of dolphinfish biological and fishing data in Japanese waters*
}

\author{
RYOICHI SAKAMOTO ${ }^{1}$ and SHUMPEI KOJIMA ${ }^{2}$ \\ ${ }^{1}$ Fisheries Administration Division, Miyazaki Prefecture, 2-10-1. Tachibana-dori-highasi, Miyazaki, 880 Japan. \\ E-mail: rsakam@orange.ocn.ne.ip \\ ${ }^{2}$ ex-Shimane Prefectural Fisheries Experimental Station, 2139-15. Aioi-machi, Hamada, Shimane, 697 Japan.
}

\begin{abstract}
SUMMARY: The dolphinfish (Coryphaena hippurus) performs seasonal migrations into adjacent waters of Japan, where it is exploited by several fisheries. The annual dolphinfish landings in Japan have tended to decrease in recent years. Between 1993 and 1995, the mean annual catch was 9962 metric tonnes. This total catch corresponded to the following fishing methods: set net fishery $24.9 \%$, skipjack pole and line fishery $21.2 \%$, surrounding net fishery (which is mainly comprised of the "shiira-zuke" fishery) $12.9 \%$, longline fishery $10.2 \%$, other angling fisheries $10.3 \%$, and other fisheries $20.5 \%$. In the "shiira-zuke" fishery, fishermen catch dolphinfish and other fishes gathering around bamboo rafts (called "tsukegi") with a purse seine net. Major fishing grounds of this fishery are situated in the western Japan Sea and off the south Pacific Japanese coast. The use of floating FADs to create productive fishing areas is of ecological interest. In this paper we describe this fishery, and review the biological characteristics of dolphinfish with regard to ecology and fishing conditions.
\end{abstract}

Keywords: Dolphinfish, Coryphaena hippurus, Fisheries, Biology, Western Pacific.

\section{INTRODUCTION}

In the Pacific Ocean, the dolphinfish (Coryphaena hippurus) is found year round in waters within latitude $30^{\circ}$ (Kojima, 1964a). From early summer to autumn, this species performs seasonal migrations into the adjacent seas of Japan, where it is the target of important fisheries.

Surface migratory fishes such as dolphinfish, skipjack (Katsuwonus pelamis) and yellowfin tuna (Thunnus albacares) are well known to gather under floating objects like driftwood and floating seaweed. The Japanese "shiira-zuke" fishery captures mainly dolphinfish which gather under bamboo rafts (called "tsukegi") set on the sea surface. Although the use

*Received October 23, 1997. Accepted April 20, 1999. of FADs (Fish Aggregation Devices) in unused offshore areas, with surface migratory fishes as targets, has attracted attention over the years, much remains unknown about the gathering mechanism or the fish collecting effect of these FADs. Several studies in Japanese waters have examined biological aspects of the "shiira-zuke" fishery (e.g. Kojima, 1955, 1956, 1960a, 1960b, 1961, 1963a, 1963b, 1964b, 1966a, 1966b, 1967, Ida et al., 1967; Sakamoto and Taniguchi, 1993).

Here we review information on dolphinfish fisheries in Japanese waters, as well as data on the biology of this species in the area. In particular, we review the ecological aspects and fishing conditions (fishing data, seasonal changes, length distribution, growth, feeding habits and fish community associated with "tsukegi") of the "shiira-zuke" fishery. 


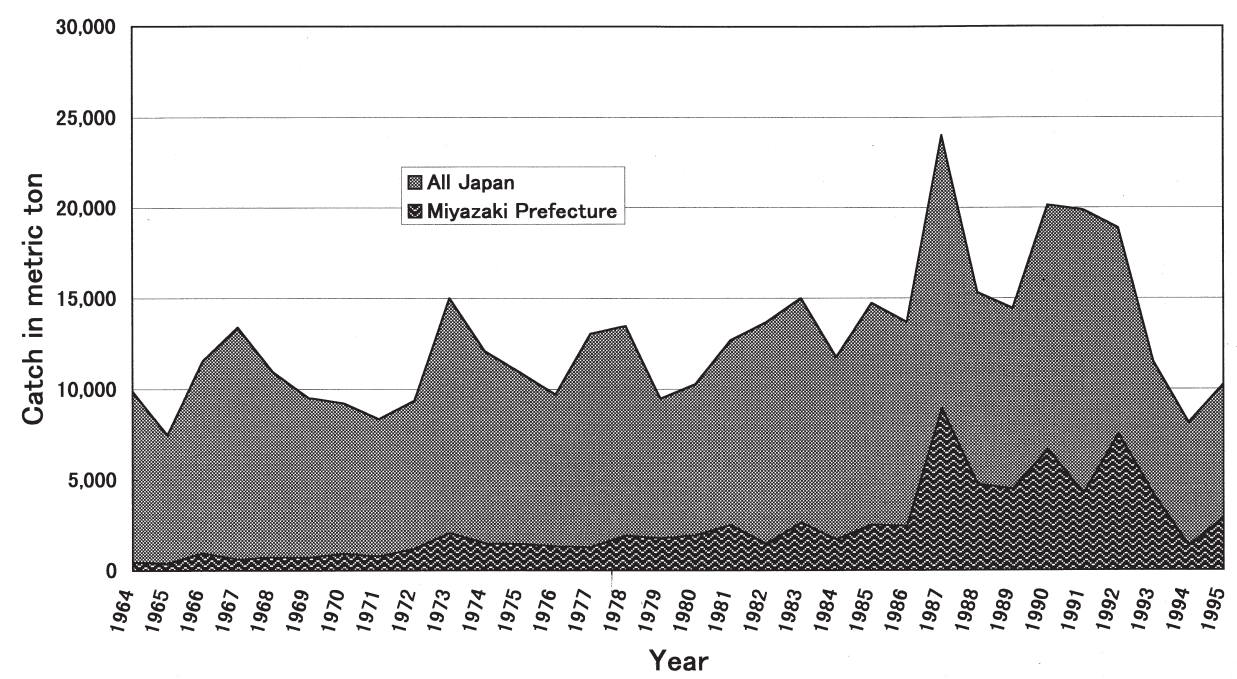

FIG. 1. - Historic catch data series of dolphinfish in all of Japan and in Miyazaki Prefecture.

\section{PRODUCTION TRENDS}

The annual catches of dolphinfish in Japan tended to increase from 1964 to 1987 (Fig. 1). Following a peak catch of 24019 metric tonnes in 1987, the annual catch decreased in 1988-1989. In recent years (1993-1995) the mean annual catch of dolphinfish has been 9962 metric tonnes, with a mean annual value of $¥ 1785$ million. This overal trend is consistent with that seen in Miyazaki Prefecture, a major dolphinfish fishing area (Fig. 1). The recent mean annual catch (1993-1995) in Miyazaki Prefecture has been 2775 metric tonnes of dolphinfish,
TABLE. 1. - Annual catches (metric tons) of dolphinfish by regions in adjacent waters of Japan. Statistics based on home ports.

\begin{tabular}{lrrrrrrr}
\hline Sea region & 1989 & 1990 & 1991 & 1992 & 1993 & 1994 & 1995 \\
\hline Hokkaido & 110 & 285 & 105 & 131 & 15 & 102 & 61 \\
North Pacific & 457 & 630 & 1006 & 1502 & 39 & 85 & 85 \\
Middel Pacific & 1362 & 2214 & 4509 & 1512 & 860 & 912 & 1238 \\
South Pacific & 6849 & 10111 & 9136 & 10205 & 6007 & 2469 & 4782 \\
North Japan Sea & 575 & 1043 & 710 & 634 & 155 & 537 & 811 \\
West Japan Sea & 2145 & 2337 & 1172 & 1654 & 1686 & 1252 & 1122 \\
East China Sea & 2919 & 3509 & 3210 & 3226 & 2707 & 2777 & 2088 \\
Seto Inland Sea & 10 & 16 & 21 & 8 & 27 & 9 & 15 \\
& & & & & & & \\
Total & 14427 & 20145 & 19869 & 18872 & 11496 & 8143 & 1024 \\
& & & & & & &
\end{tabular}

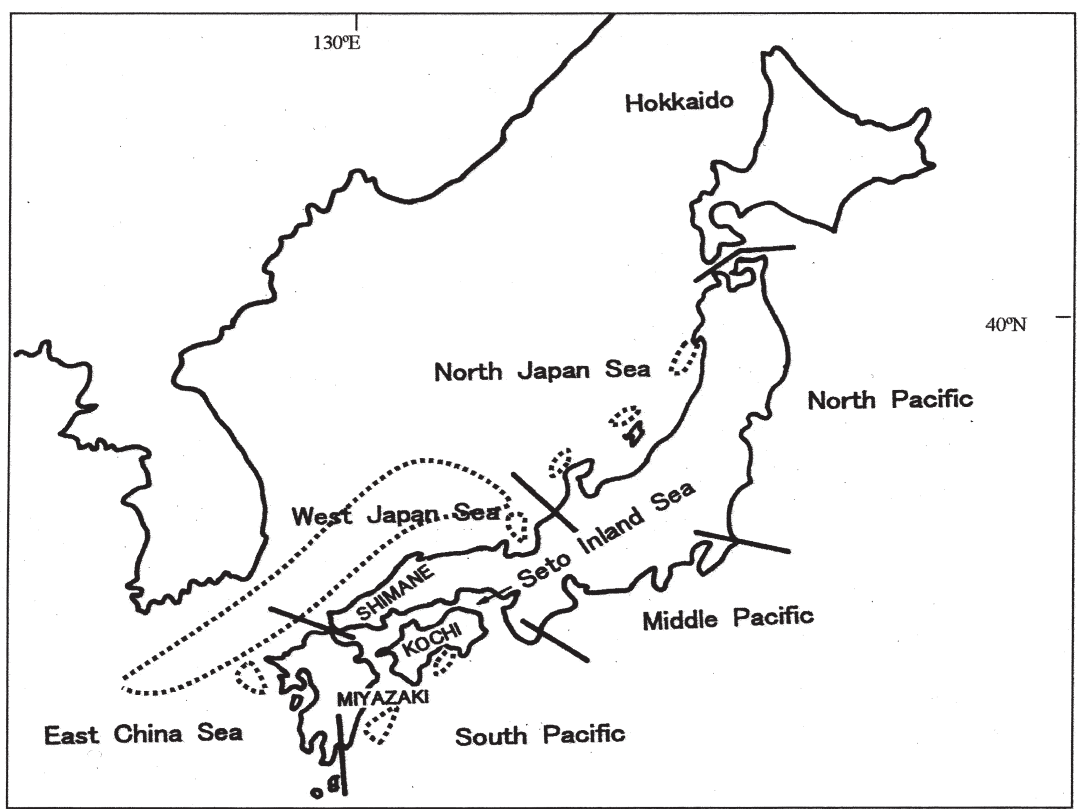

FIG. 2. - Regions of adjacent waters of Japan and distribution of "shiira-zuke" fishing grounds (dotted areas). 


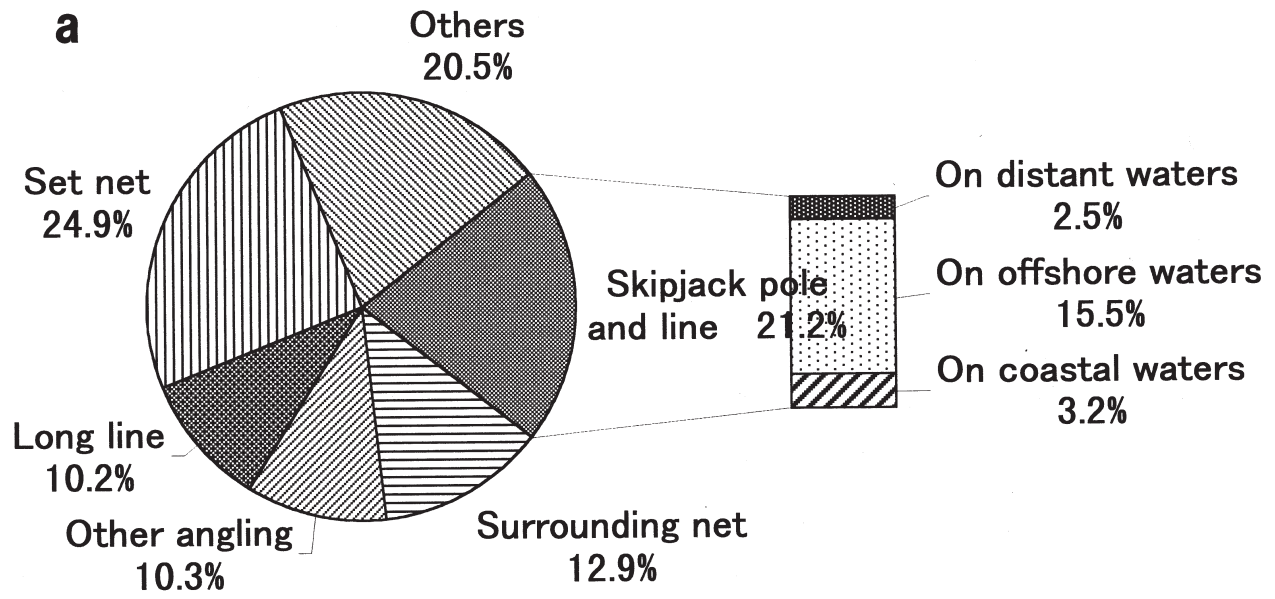

Total catch $=9,962$ ton

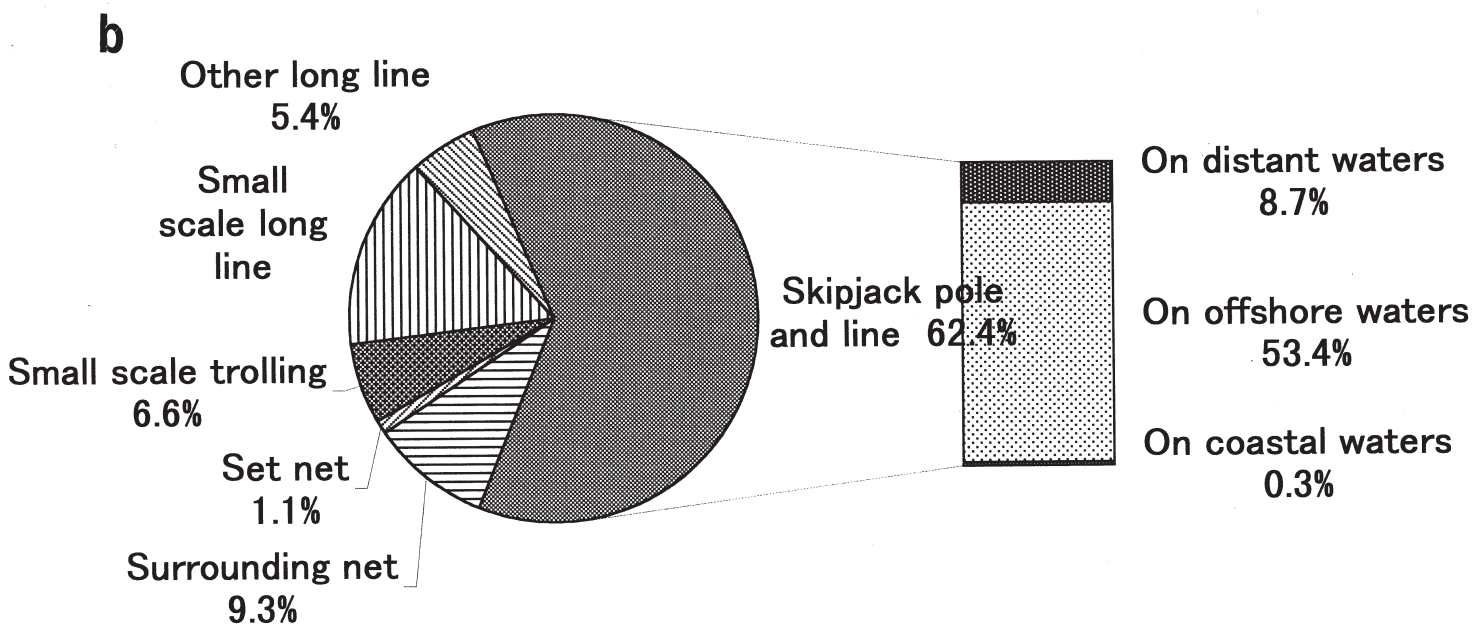

\section{Total catch $=2,775$ ton}

FIG. 3. - Mean annual catch (1993-1995) of dolphinfish by fishing methods in Japan (a) and in Miyazaki Prefecture (b). The percentage of dolphinfish catches by fishing area in the skipjack pole and line fishery is also shown.

with a mean annual value of $¥ 603$ million. Annual catches of dolphinfish by regions (Fig. 2) from 1989 to 1995 (Table 1) indicated that the South Pacific and East China Sea are responsible for two thirds of Japan's total production.

Mean annual catch (1993-1995) of dolphinfish by fishing methods in Japan and in Miyazaki Prefecture are given in Fig. 3. The most important portion of dolphinfish is caught in the skipjack pole and line fishery. Its major offshore fishing areas, where dolphinfish is captured as by-catch, change with seasonal migration of skipjacks (Fig. 4). Other important fisheries for dolphinfish are the surrounding net fishery, which is comprised mostly of the "shiira-zuke" fishery, the set net fishery and the longline fishery.
The seasonal pattern of dolphinfish landings in seven major markets of Miyazaki Prefecture from 1993 to 1995 is shown in Fig. 5. Although dolphinfish is captured all year round, about $70 \%$ of the catch is landed from April to June.

\section{FISHING METHODS AND FISHING AREAS}

In the trolling line fishery, 1-5 metric ton vessels use cutriggers to tow 2 main surface lines and several subsurface lines, each bearing 1 to 3 hooks and artificial baits. They operate from June to August between 5 and 30 miles from shore (Yamaguchi, 1977). The longline fishery uses 3-10 metric ton vessels which deploy 10-16 Km of multihook, sub- 


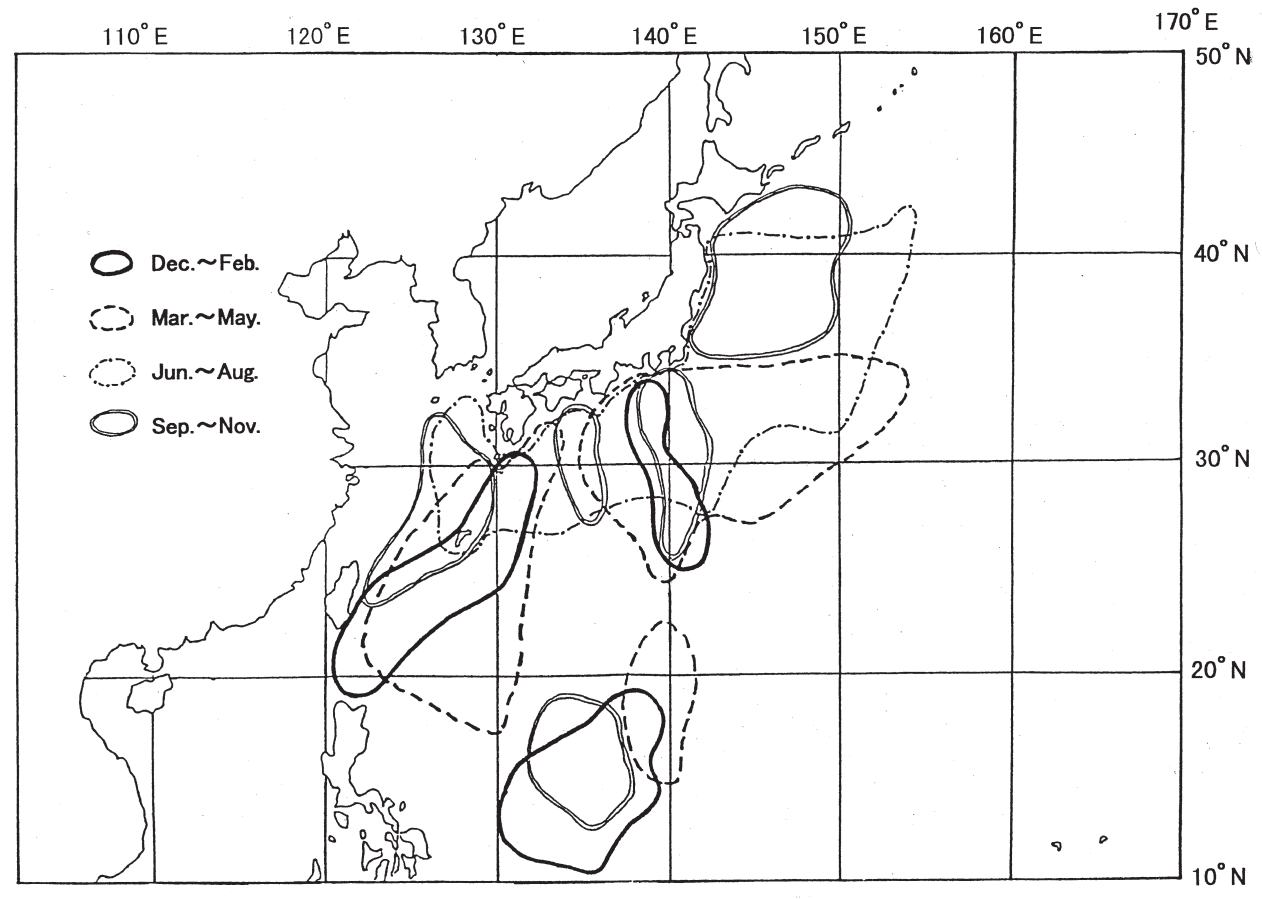

FIG. 4. - Seasonal fishing grounds of the skipjack pole and line fishery in offshore waters of Japan. Data source: "Adjacent Sea Skipjack and Tuna Fishery" by the Japan Fisheries Association and National Association Adjacent Sea Skipjack and Tuna Fishery (1989).

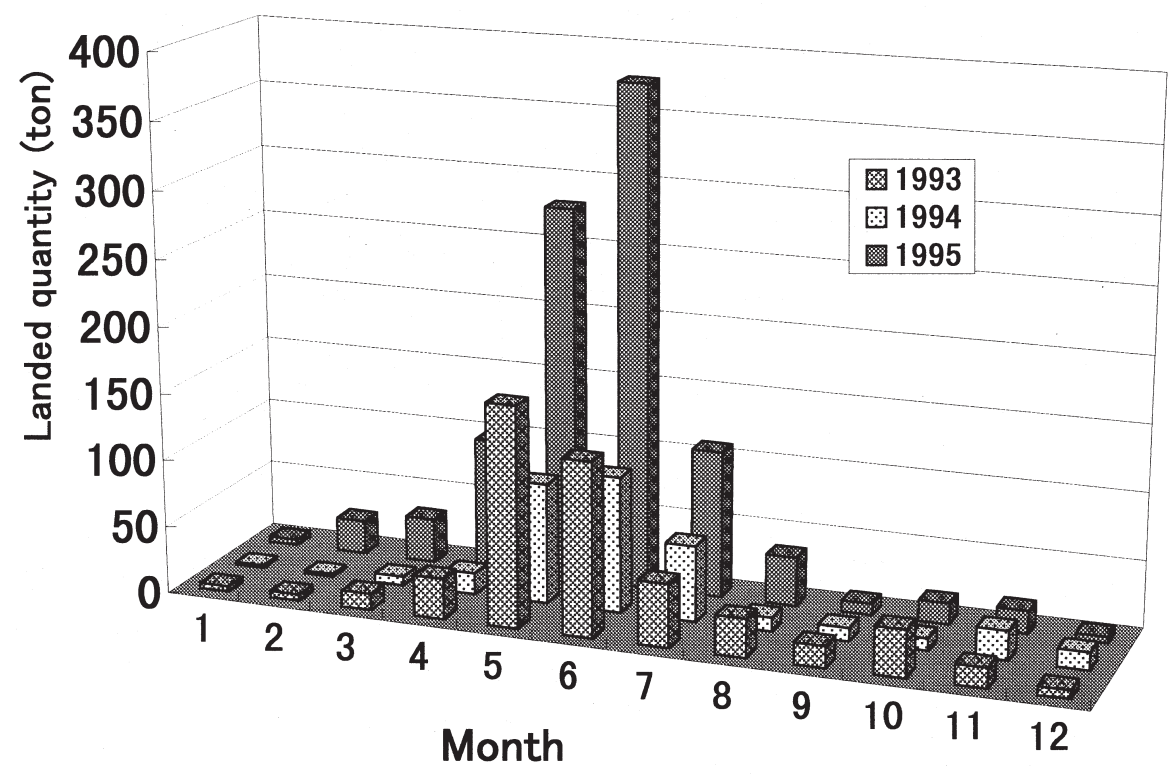

FIG. 5. - Monthly distribution of dolphinfish landings in seven major markets of Miyazaki Prefecture from 1993 to 1995.

surface (9-12 m depth) longlines. They also operate between 5 and 30 miles from shore between May and July (Kaveda, 1995).

In the "shiira-zuke" fishery, anchored bamboo rafts (called "tsukegi") are used, and dolphinfish and other fishes gathering around are caught with a purse seine net. The "shiira-zuke" fishery is a traditional fishery targetting mainly dolphinfish, although in recent years the fishery captured mainly amberjack (Seriola lalandi) along the west coast of East China Sea. Major fishing grounds (Fig. 2) are situated in the western Japan Sea (Shimane Prefec- 

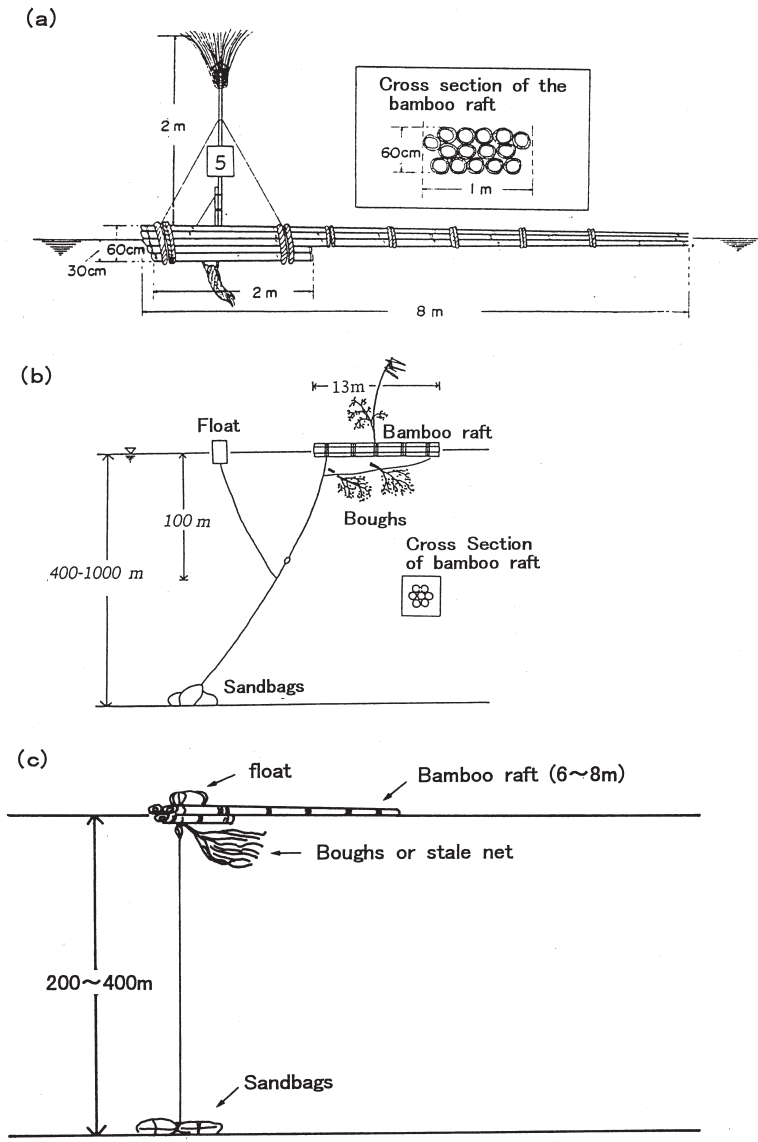

FIG. 6. - Design of "tsukegi" (bamboo raft for dolphinfish used in the "shiira-zuke fishery) typical of Shimane (a), Kochi (b) and Myyazaki (c) districts.

ture) and off the Japanese coast in the western Pacific (Miyazaki and Kochi Prefectures). The use of anchored FADs restricts the fishing grounds to relatively shallow waters over the continental shelf, and to areas without strong currents. In the Kochi district, they are situated 30-40 miles off the shore and over $1000 \mathrm{~m}$ depth. During the fishing season (JuneNovember) more than 2000 "tsukegi" may be set over this area, and to avoid the excessive competition for sea space, the setting line of respective "tsukegi" is decided by lottery every year, such that in principle a vessel will only operate along the assigned line, except in cases of co-operation with other vessels.

The designs of the "tsukegi" typical of the Shimane, Kochi and Miyazaki districts are shown in Fig. 6. In the Kochi and Miyazaki districts, a green wood of bayberry is tied below the "tsukegi", because fishermen consider that this "darkness" (the bush) has a crucial effect on aggregation of dolphinfish, and replace the bayberry branches once or twice a month to prevent the falling and browning of leaves. The purse seine net used is about $180 \mathrm{~m}$ long on its buoy side. The net height is approximately $10.5 \mathrm{~m}$ in the bag and $3.3 \mathrm{~m}$ in the wings. The mesh size is approximately $3 \mathrm{~cm}$ in the bag and $6 \mathrm{~cm}$ in the wings. Vessels operating in the "shiira-zuke" fishery are between 5 and 18 metric tons and have 45-140 horse power. A single boat's crew usually consists of 2 persons.

The fishing operation around each "tsukegi" is carried out as follows. Mackerel slice are scattered as chum, whilst baits of rainbow runner (Elagatis bipinnulata) and buller mackerel (Auxis rochei) are towed, and artificial mongrel mackerel (Acanthocybium solandri) and dolphinfish (tubular streamers made of cloth) are used to lure the gathered fishes out from under the "tsukegi". The purse seine is then cast around the lure school. Reactions to the chum differ between species. For example, compared to the dolphinfish, rainbow runner and greater amberjack (Seriola dumerili) are much more difficult to lure away as a school. Catchability also differs between species, and dolphinfish cannot escape the purse seine by cruising vertically like some other fish (e.g. skipjack, yellowfin tuna and mongrel mackerel). These species are not easily captured by purse seine nets, and have to be caught by piercing with a hook or harpoon.

TABLE 2. - Fishes taken around "tsukegi" by the "shiira-zuke" fishery along Kochi Prefecture during June through November 1985 (from Sakamoto and Taniguchi, 1993).

\begin{tabular}{lccr}
\hline & \multicolumn{2}{c}{ Length(cm) } & Sample \\
Species & Range & Mode & size \\
\hline Elagatis bipinnulata & $16.7-79$ & $29-30$ & 422 \\
Seriola quinqueradiata & 34 & - & 1 \\
Seriola rivoliana and S. dumerili & $15.6-48$ & $24-26$ & 256 \\
Seriola lalandi & 35 & - & 1 \\
Naucrates ductor & $23.5,27.5$ & - & 2 \\
Decapterus macarellus & $18-45$ & $22-24$ & 176 \\
Kaiwarinus equula & 19 & - & 1 \\
Caranx sexfasciatus & 25.5 & - & 1 \\
Uraspis helvola & $14.5-29.2$ & $20-22$ & 167 \\
Carangoides orthogrammus & $18-28$ & $24-28$ & 21 \\
Carangoides ferdau & 21.5 & - & 1 \\
Coryphaena hippurus & $27-130$ & $48-50$ & 1111 \\
Lobotes surinamensis & $25.5-49$ & 47 & 7 \\
Kyphosus lembus & $14-33$ & - & 18 \\
Kyphosus cinerascens & $9-25.5$ & $12-13$ & 5 \\
Oplegnathus fasciatus & 15.5 & - & 1 \\
Oplegnathus punctatus & 16 & - & 1 \\
Acanthocybium solandri & $44-136$ & $80-90$ & 136 \\
Katsuwonus pelamis & $25.5-35.5$ & $26-27$ & 43 \\
Auxis rochei & $35-37$ & - & 3 \\
Thunnus albacares & $25-63$ & $38-40$ & 23 \\
Thunnus alalunga & $33-44$ & - & 6 \\
Aluterus monoceros & $12-46.5$ & $36-38$ & 197 \\
& & & \\
\hline & & &
\end{tabular}




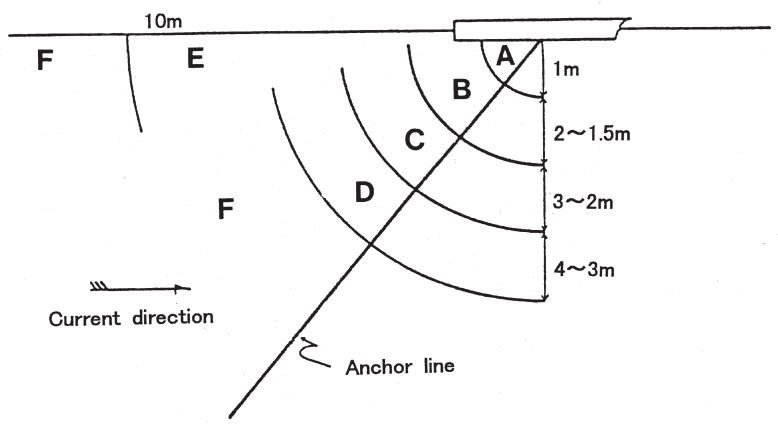

FIG. 7. - Spatial distribution of fish species around "tsukegi" in the Shimane Prefecture (from Kojima, 1966c).

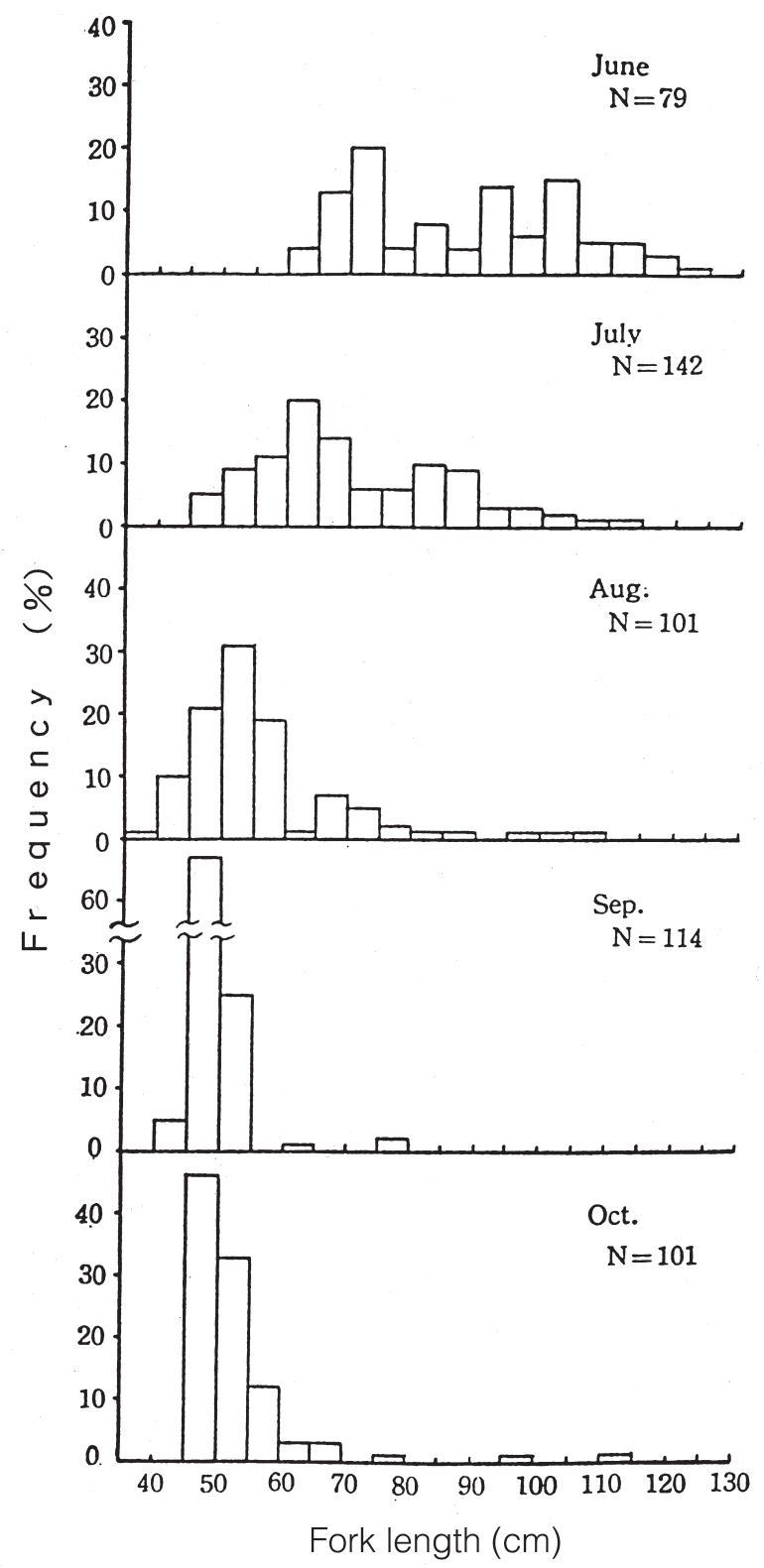

FIG. 8. - Monthly size distributions for dolphinfish caught by the "shiira-zuke" fishery in the western Japan Sea off Shimane Prefecture during the 1964 fishing season (from Kojima, 1966b).

\section{“TSUKEGI” FISH AGGREGATIONS}

Table 2 shows the species composition of "tsukegi" fish aggregations. The absence in the catches of small fishes that are thought to be beneath the "tsukegi" is most likely a result of their not being vulnerable to the fishing method and gear. Because catchability differs clearly between species, the results obtained might not reflect faithfully the actual ratios of species and quantity of fishes gathering around the "tsukegi".

However, these data allow the identification of much of the fish fauna gathering around the "tsukegi". Dolphinfish was overwhelmingly the most numerous species, followed by Elagatis bipinnulata, Seriola dumerili, Seriola rivoliana, Aluterus monoceros, Decapterus macarellus, Urasois helvola and Acanthocybium solandri. Body length ranged widely from Kyphosus cinerasecens of $9 \mathrm{~cm}$ to A. solandri of $136 \mathrm{~cm}$. Thunnus albacares, Thunnus alalunga, S. dumerili, S. rivoliana, and E. bipinnulata were found to gather around the "tsukegi" as young immature fish.

The spatial distribution of fishes around the "tsukegi" has a characteristic pattern (Fig. 7). Dolphinfish usually swim about 10-15 m up current from the "tsukegi", and are seldom seen in any other place. All the fish attracted to "tsukegi" tend to stay parallel to it, gathering either around the anchor line or the head of the raft against the current. Among the various species schooling about the raft, the smallest was Girella punctata of about $5 \mathrm{~cm}$ in length. Fishes staying at the "tsukegi" are those which have grown enough to resist the current.

\section{BIOLOGICAL DATA}

The monthly size distribution of dolphinfish caught in the western Japan Sea (Fig. 8) shows that early in the season (June) schools are composed mainly of large fishes of more than $60 \mathrm{~cm}$ fork length (FL), and after August they are mainly composed of small fishes of about $50 \mathrm{~cm}$ FL. Based on Kojima (1966a, 1966b), dolphinfish larger than 55 $\mathrm{cm}$ FL were fully mature, so this seasonal variation in size represents the appearance of spawning schools (older fish) and feeding schools (young fish).

Simmilar trends can be observed in the southern Pacific Japanese coast (Fig. 9), where large size fish (over $80 \mathrm{~cm} \mathrm{FL)} \mathrm{were} \mathrm{identified} \mathrm{as} \mathrm{the} \mathrm{main} \mathrm{group}$ 

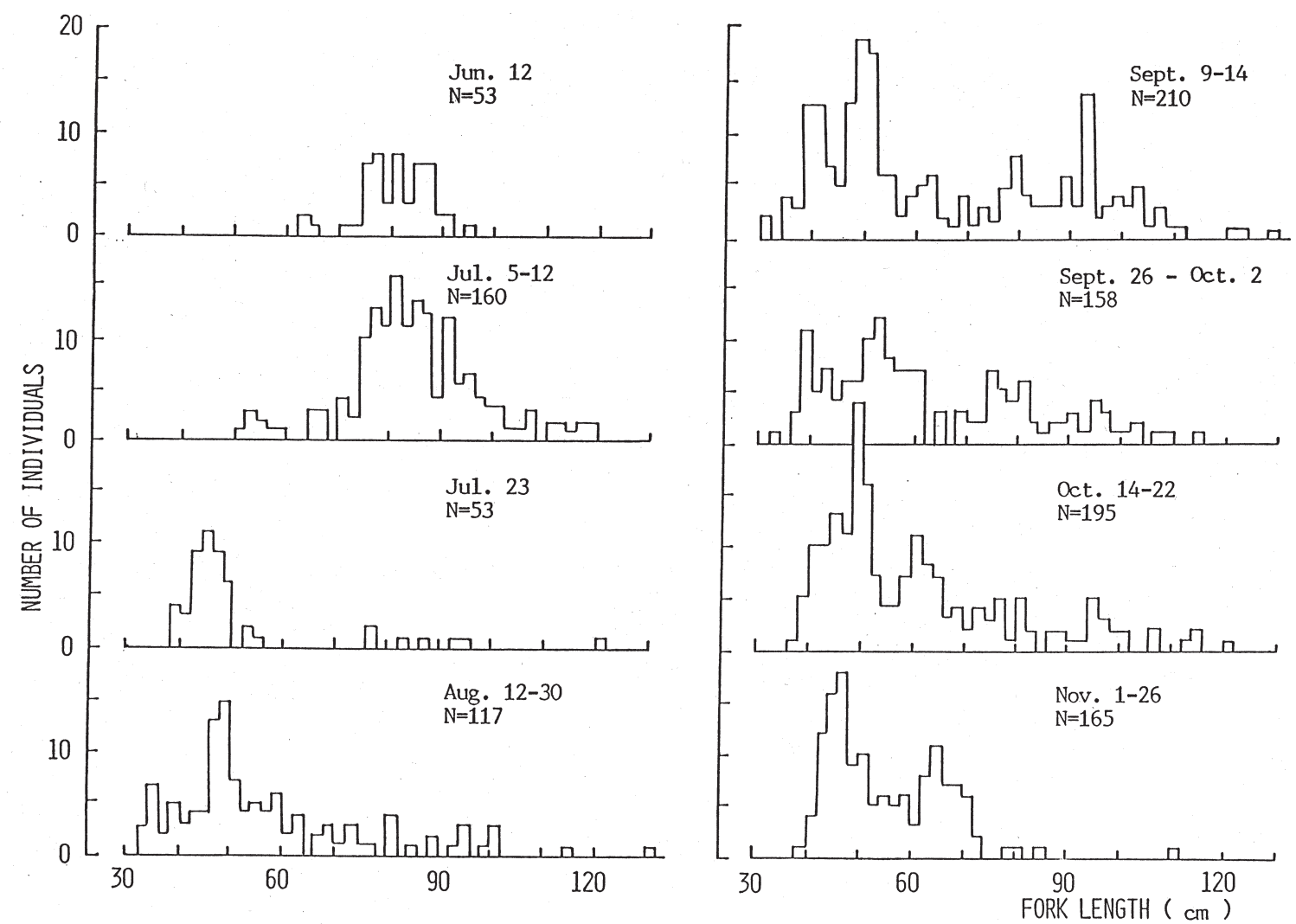

FIG. 9. - Monthly size distributions for dolphinfish caught by the "shiira-zuke" fishery in the southern Pacific Japanese coast off Kochi Prefecture during the 1985 fishing season (from Sakamoto and Taniguchi, 1993).

until the middle of July, and small size fish (45-50 $\mathrm{cm}$ FL) became the main group after late July. This pattern is consistent with that reported in the Japan Sea, except for the occurrence of a well defined large size group in July, which appears relatively often until late October. Furthermore, the modal length of about $45 \mathrm{~cm}$ FL in late July increases over the months to about $65 \mathrm{~cm}$ FL in November. From September to October, individuals with a mode of 40-50 cm FL appear, and in November the size distribution is clearly bimodal.

In Japanese waters, dolphinfish reach about 38 $\mathrm{cm}$ FL by the first year, $68 \mathrm{~cm}$ FL by the second year, $90 \mathrm{~cm}$ FL by the third year, $108 \mathrm{~cm}$ FL by the fourth year and $122 \mathrm{~cm}$ FL by the fifth year. However, growth rates observed in reared specimens were higher, and in the aquarium young specimens of $45 \mathrm{~cm}$ and $0.5 \mathrm{Kg}$ were grown to the size of 123 $\mathrm{cm}$ and $16.6 \mathrm{Kg}$ in 9 months (Masuda et al., 1975). Furthermore, of 36 young dolphinfish between 35 and $50 \mathrm{~cm}$ total length (TL) collected in SeptemberOctober 1975 and kept in a big tank at $22.8-25.4^{\circ} \mathrm{C}$, 11 specimens survived until April 1976, at which time they had increased in length to about $100 \mathrm{~cm}$ TL (Soichi, 1978).
Feeding habits of dolphinfish have been extensively studied in Japanese waters. From 1103 specimens between 35 and $105 \mathrm{~cm}$ in length captured in the Japan Sea, Kojima (1961) found that fishes made up $85 \%$ of the food items by frequency of occurrence and $95 \%$ by weight. The food items appeared, for the most part, to fall into two size groups: 2-4 cm (e.g. Stephanolepis cirrhifer, Engraulis japonicus and Upeneus bensani) and 10$15 \mathrm{~cm}$ (e.g. E. japonicus, Sardinops melanostictus and flyingfishes). The same author concluded that the diet of dolphinfish changes during the early development (Kojima, 1966c). Thus, juveniles up to $4 \mathrm{~cm}$ TL mainly feed on Copepoda, and thereafter they begin to feed on other juvenile fish such as Cololabis saira, Seriola quinqueradiata, Girella punctata and Stephanolepis cirrhifer. Young fish $>18 \mathrm{~cm}$ TL feed mainly on pelagic juvenile fishes such as E. japonicus, $U$. bensasi and flyingfishes.

Similar results were obtained by Sakamoto and Taniguchi (1993) from adult dolphinfish captured by the "shiira-zuke" fishery in the western Pacific Japanese coast. From 575 samples, 306 individuals were detected to contain food. Fishes were overwhelmingly the most numerous group in the stom- 

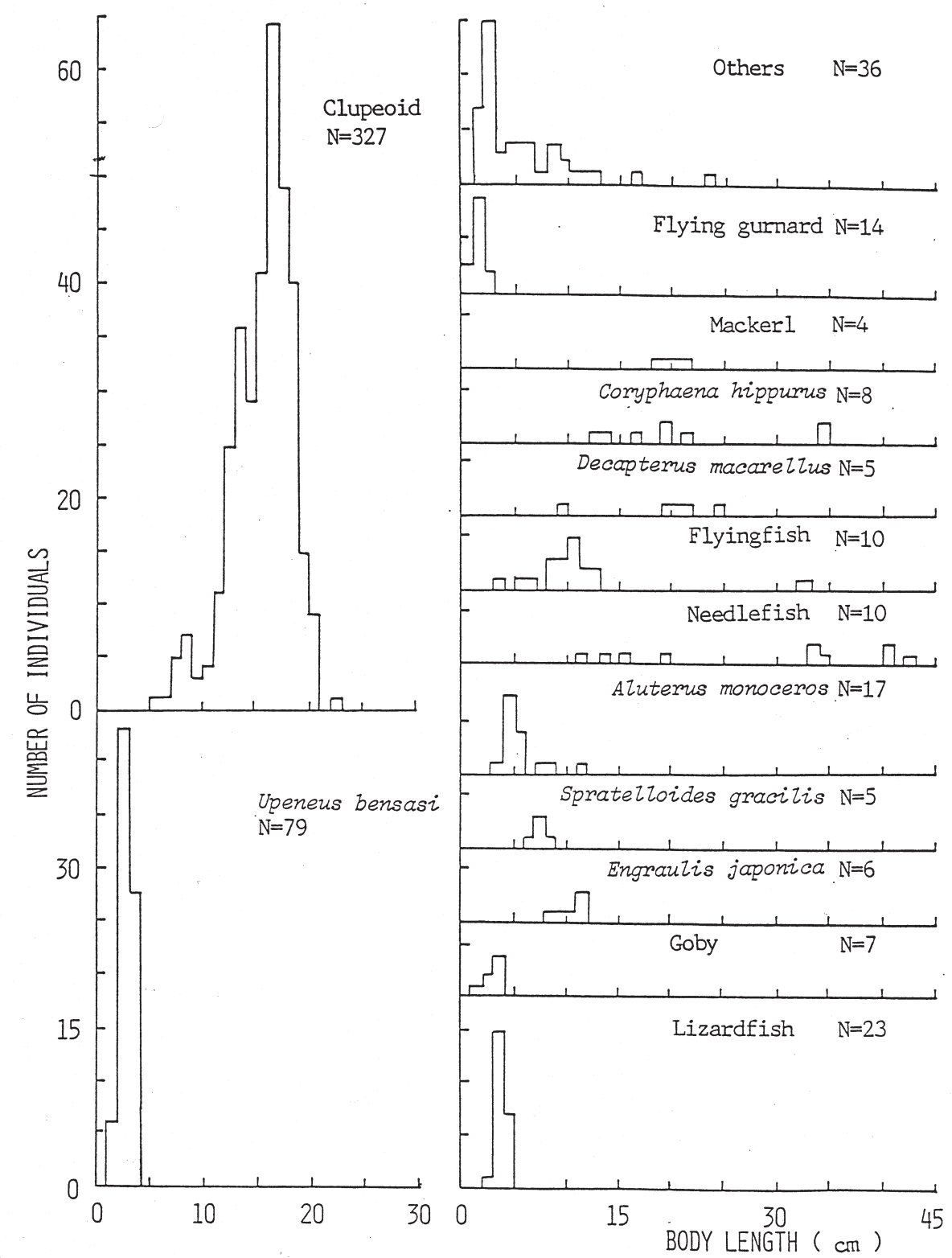

FIG. 10. - Body length composition of each food item found in the stomach contents of dolphinfish caught by "shiira-zuke" fishery off Kochi Prefecture in 1985 (from Sakamoto and Taniguchi, 1993).

ach contents, accounting for $86.7 \%$ of the total number of prey items and $98.4 \%$ of the total weight; clupeids (including S. melanostictus, Etrumeus teres, $E$. japonicus and other unidentifiable species) were the most frequenct preys, occurring in $68 \%$ of all stomachs. In total, fishes from 24 families and 35 species were identified as prey of dolphinfish, with $S$. melanostictus occuring in $51 \%$ of all stomachs containing food and accounting for $63.8 \%$ of the total weight of prey items. The next most frequently occurring species was $U$. bensasi, which was found in $11.8 \%$ of all stomachs and accounted for $13.5 \%$ of all prey items by number and $0.2 \%$ by weight. It was found that prey size varied widely, from $1 \mathrm{~cm}$ to about $35 \mathrm{~cm}$ (Fig. 10), but size distribution of prey was distinctly bimodal: one mode below $4 \mathrm{~cm}$ and the other around 15-20 cm, which was consistent with the former knowledge in the Japan Sea (Kojima, 1961).

The diet of dolphinfish varied during its ontogenic development (Fig. 11). The smaller the body length class was, the more juvenile fish occurred in the stomach contents. Inversely, the bigger the predator was, the more large size prey appeared. By groups, clupeids were important in all size classes of dolphinfish. For invertebrate prey, crustaceans were 


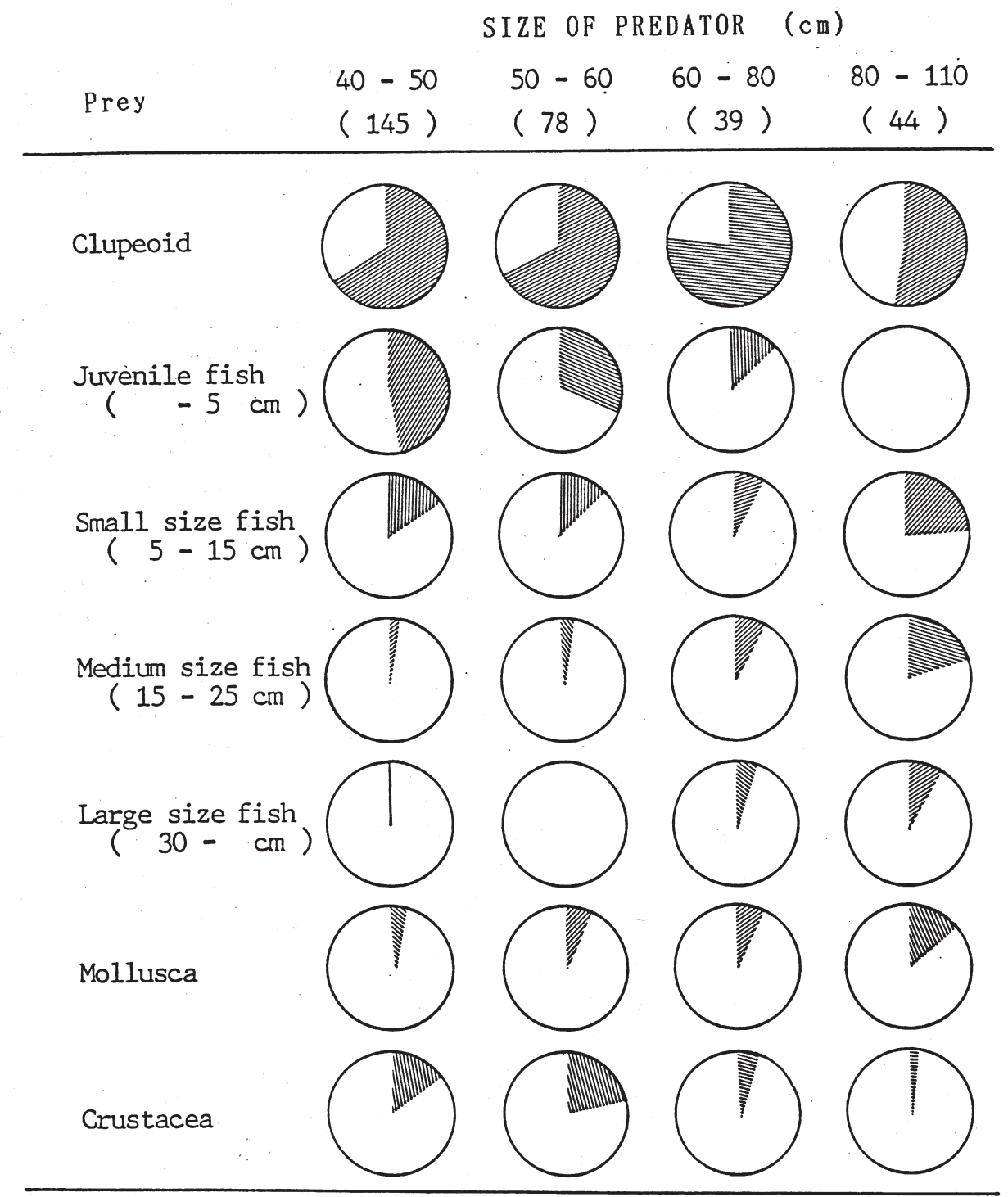

FIG. 11. - Frequency of occurrence (as percentage) for selected prey items of dolphinfish, stratified by predator size, off Kochi Prefecture in 1985 (from Sakamoto and Taniguchi, 1993).

found more frequently in fish of smaller size, and molluscs occurred more often in the stomachs of fish of larger size. Daily changes in feeding activity have been analysed by Sakamoto and Taniguchi (1993). The comparison of degree of digestion of stomach contents between dolphinfish caught in the morning and in the afternoon indicate that dolphinfish feed more actively in the morning than in the afternoon.

Seasonal changes in the diet of dolphinfish have also been observed. In most of the stomachs analysed from the Japan Sea, medium sized fish exceeded juveniles in amount (Kojima, 1963b). Nevertheless, species composition of medium sized fish in the stomachs changed 2 or 3 times within each of the three fishing seasons considered. During this period of alternation, medium sized fish decreased while juveniles increased in amount. Based on the above observations, it can be considered that dolphinfish feed mainly on medium sized fish, but sometimes on juveniles when the primary food becomes scarce. In the southern Pacific Japanese coast (Sakamoto and Taniguchi, 1993), clupeids occurred with high frequency over all seasons (Fig. 12). Nevertheless, juvenile fish $(<5 \mathrm{~cm}$ length $)$ appeared with high frequency in August and September, and small sized fish (5-15 cm length) occurred with high frequency from June to September. Molluscs occurred frequently in June and August, and crustaceans appeared from August to 


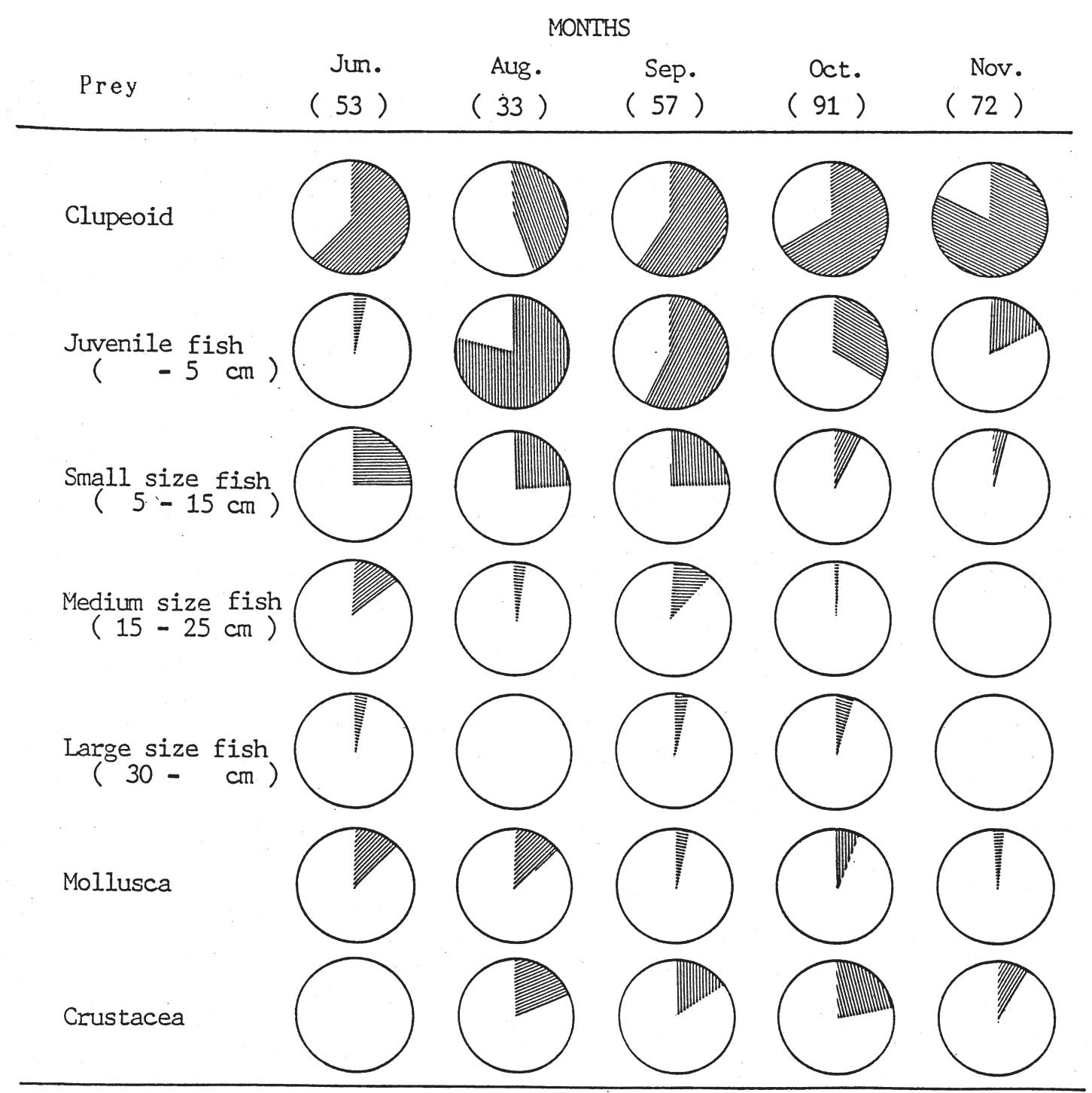

FIG. 12. - Frequency of occurrence (as percentage) for selected prey items of dolphinfish, stratified by month, off Kochi Prefecture in 1985 (from Sakamoto and Taniguchi, 1993).

October. In any case, prey selection of dolphinfish was basically not strong, and dolphinfish can be defined to be opportunistic feeders that catch preys which live near the very surface and in sizes they can catch. Thus, these seasonal changes in the diet of dolphinfish may be related to changes in the prey environment and to a different size composition of the dolphinfish population.

\section{REFERENCES}

Ida, H., Y. Hiyama and T. Kusaka. - 1967. Study on fishes gathering around floating seaved-II. Behaviour and feeding habits. Bull. Jap. Soc. Sci. Fish., 33(10): 472-478.

Kaneda, Y. - 1995. Fisheries and fishing methods of Japan. Seizando, Tokyo, $214 \mathrm{pp}$.
Kojima, S. - 1955. A study of dorado fishing condition in the western part of the Japan sea. Bull. Jap. Soc. Sci. Fish., 20(12): 1044-1049.

Kojima, S. - 1956. Fishing for dolphins in the western part of the Japan Sea-II. Why do the fish take shelter under floating materials? Bull. Jap. Soc. Sci. Fish., 21(10): 1049-1052.

Kojima, S. - 1960a. Fishing for dolphins in the western part of the Japan Sea-V. Species of fishes attracted to bamboo rafts. Bull. Jap. Soc. Sci. Fish., 26(4): 379-382.

Kojima, S. - 1960b. Fishing for dolphins in the western part of the Japan Sea-VI. Behaviours of fish gathering around bamboo rafts. Bull. Jap. Soc. Sci. Fish., 26(4): 383-388.

Kojima, S. - 1961. Studies on fishing conditions of dolphin, Coryphaena hippurus L., in the western region of the Sea of Japan-III. On food contents of the dolphin. Bull. Jap. Soc. Sci. Fish., 27: 625-629.

Kojima, S. - 1963a. Studies on fishing conditions of the dolphin, Coryphaena hippurus L., in the western region of the Sea of Japan-VII. Relationships between the stomach contents and the pelagic fauna of juveniles. Bull. Jap. Soc. Sci. Fish., 29(5): 407414.

Kojima, S. - 1963b. Studies on fishing conditions of the dolphin, Coryphaena hippurus L., in the western region of the Sea of 
Japan-VIII. Comparision of juvenile fish fauna in the sea and in the stomachs of dolphin. Bull. Jap. Soc. Sci. Fish., 29(6): 507-513.

Kojima, S. - 1964a. On the distribution of the dolphin, Coryphaena hippurus L., in the Pacific Ocean and the Indian Ocean. Bull. Jap. Soc. Sci. Fish., 30(6): 472-477.

Kojima, S. - 1964b. Studies on fishing conditions of the dolphin, Coryphaena hippurus L., in the western regions of the Sea of Japan-IX. Quantitative analysis on stomach contents. Bull. Jap. Soc. Sci. Fish., 30(8): 619-623.

Kojima, S. - 1966a. Studies on fishing conditions of the dolphin, Coryphaena hippurus, in the western regions of the Sea of Japan-XI. School of dolphins accompanying various kinds of flotages. Bull. Jap. Soc. Sci. Fish., 32(8): 647-651.

Kojima, S. - 1966b. Studies on fishing conditions of the dolphin, Coryphaena hippurus, in the western regions of the Sea of Japan-XII. The size of a dolphin school. Bull. Jap. Soc. Sci.
Fish., 32(8): 652-654.

Kojima, S. - 1967. Studies on fishing conditions of the dolphin, Coryphaena hippurus, in the western regions of the Sea of Japan-XIII. "Tsukegi" as a source of food for dolphins. Bull. Jap. Soc. Sci. Fish., 33(4): 320-324.

Masuda H., C. Araga and T. Yoshino. - 1975. Coastal fishes of southern Japan. Koseisya Koseikaku, Tokyo, 379 pp.

Sakamoto, R and N. Taniguchi. - 1993. Stopmach contents of dolphinfish, Coryphaena hippurus, caught around bamboo rafts in Tosa Bay, the waters Southwestern Japan. Bull. Jap. Soc. Fish. Oceanogr. Suisan Kaiyo Kenkyo, 57(2): 17-29.

Soichi, M. - 1978. Spawning behaviour of the dolphin, Coryphaena hippurus, in the aquarium and its eggs and larvae. Jpn. J. Ichthyol., 24: 290-294.

Yamaguchi K. - 1977. Trolling line fishery in West Japan. Fish. Exp. Sta. Subcommittee. Koseisya Koseikaku, Tokyo. 